\section{Surgical Scrubs}

Note:

The following letter from Drs. Paul and Mary Anne LaRocca was received in June 1986. The Editor apologizes for the lengthy delay between receipt and publication.

\section{To the Editor:}

As clinical researchers involved in conducting rigidly controlled, statistically sound, clinical studies involving antiseptic preparations using the "glove juice" procedure, we are compelled to comment on "Brief Report: The Antiseptic Efficacy of Chlorxylenol-Containing vs. Chlorhexidine Gluconate-Containing Surgical Scrub Preparations" (Soulsby ME, Barnett JB, Maddox S: Infect Control 1986; 4:223-226).

The authors state that their study was "designed after the criteria set forth in the guidelines developed for review of antiseptics as to their safety and efficacy by the FDA." However, there are some significant deviations from these guidelines in the procedures described, and some other issues explained below that lead one to question the validity of the entire study.

1. Instead of a minimum of 30 subjects, only 12 subjects were studied. This means that only three hands were available for the 3- and 6-hour evaluations of each product, too few for reliable statistical analysis.

2. The comparison was between a prepackaged commercial Anti-Sept ${ }^{\circledR}$ sponge-brush containing a standardized amount of PCMX and a dry sponge-brush with Hibiclens ${ }^{\circledR}$ applied "as needed" (no amount given). Why didn't the authors use prepackaged Hibiclens sponge-brushes, which are also commercially available and which contain a standardized amount of chlorhexidine gluconate and a special foam to ensure that the chlorhexidine gluconate is not bound to the sponge material? The present study may have actually been a comparison of AntiSept with an inadequate amount of Hibiclens or with Hibiclens bound to the sponge material.

3. It is standard practice in "glove juice" studies to prepare tenfold serial dilutions and to perform all plating in triplicate, incorporating chemical neutralizers for the antimicrobial into the diluting fluid and plating medium. In this study, single plates were apparently used, and the authors relied upon extreme sample dilution (1 mL of 1:50 dilution added to 199 mL sampling fluid to yield $1: 10,000$ ) to eliminate concern for carryover of residual antimicrobial.

4. The data presented in the two tables are very confusing, with those of Table 2 seemingly contradicted by those of Table 1. The standard procedure is to determine the logarithm, base 10 , of each individual bacteria count and then summarize the logs in terms of means and standard deviations. Thus, the mean log counts displayed in a summary table would be the mean of individual counts. The authors, however, used a different and unusual approach. They apparently first calculated the mean of the individual raw counts and then determined the log of that mean. This value is improperly called the mean log count in Table 1. The authors summarized the raw counts rather than the $\log$ counts, resulting in a possible distortion of the data.

Published results of "glove juice" studies, including our own with Hibiclens sponge-brushes ${ }^{1,2}$ and Hibiclens $^{3}$ liquid, have indicated that if Hibiclens is used correctly and the data analyzed properly, much greater log reductions will be obtained than reported in this study, explaining why
Hibiclens is used as a standard against which other formulas are evaluated.

\section{REFERENCES}

1. LaRocca MAK, LaRocca PT: An evaluation of the antimicrobial effect of a hand sponge-brush impregnated with $4 \%$ chlorhexidine gluconate (Hibiclens). Dev Ind Microbiol 1982; 23:543-546.

2. Aly R, Maibach $\mathrm{H}$ : Comparative evaluation of chlorhexidine gluconate (Hibiclens) and povidoneiodine (E-Z Scrub) sponge/brushes for presurgical hand scrubbing. Curr Ther Res 1983; 34:740-745.

3. Peterson AF, Rosenberg A, Alatary SD: Comparative evaluation of surgical scrub preparations. Surg Grnecol Obstet 1978; 146:63-65.

Paul T. LaRocca, PhD President

Mary Anne K. LaRocca, PhD Vice President Marypaul Laboratories, Inc. Sparta, New Jersey

Dr. Michael Soulsby responds to the LaRoccas' letter:

In response to the concerns expressed by Drs. Paul and Mary Anne LaRocca, dealing with our brief report on the antiseptic efficacy of chlorxylenol-containing surgical scrub preparations, I offer the following:

Concern \#1 involves the number of subjects used and the subsequent validity of the data. Indeed, it would seem that 12 subjects would be too few for such a study, but these 12 were screened prior to the study in order to avoid normal variation among individuals. Furthermore, three plates were used to determine colony count at each sampling interval, and the standard errors of the means provided in Table 2 demonstrate the "tightness" of the data as a result of these precautions.

Concern \#2 addresses the usage of a prepackaged "finite" amount of the 3\% PCMX formulation versus an "as needed" amount of the 4\% chlorhexidine formulation, containing isopropyl alcohol. Since the chlorhexi- 
dine formulation was dispensed directly onto the hands, which were subsequently scrubbed, it would be improbable that "quenching" of activity would be an issue for concern.

Regarding concern \#3, single plates were not used, rather the solutions were plated in triplicate and a mean value used. The dilution fortunately did inactivate the formulation, but it also provided a comfortable number of colonies per plate for accurate counts to be obtained.

Concern \#4 addresses an erroneous interpretation of provided data and has been carefully addressed in the October 1986 issue of Infection Control, p. 484. It is emphasized that data presented in this publication do not agree with data presented in other publications, including their own, regarding the use of the hand spongebrush impregnated with chlorhexidine gluconate. This fact may well be due to different conditions under which the experiments were performed, or it may be related to a difference in efficacy of the formulation between usage directly from the quart bottle with subsequent brushing, on the one hand, and usage in the prepackaged form, on the other hand.

Once again, I hope the information provided herein will be of value to the readers of Infection Control, and I thank you for the opportunity to respond to these points of concern.

\section{Michael E. Soulsby, PhD}

Associate Professor

Physiology/Biophysics

University of Arkansas for

Medical Sciences

Little Rock, Arkansas

\section{Homosexuality in Institutionalized Retardates}

\section{To the Editor:}

Public law 94-142, the Mentally Retarded Persons Act of 1977, and several federal district court decisions continue to provide further impetus to the return of institutionalized retardates to the community. Although the movement is viewed as an important social advance, the occasional pres- ence of hepatitis B carriers among such individuals has generated public health concerns, especially in schools. ${ }^{1}$ It is well recognized that hepatitis B infection is unusually prevalent among institutionalized retardates and that carrier rates are high, especially among Down's syndrome subjects. ${ }^{2}$ Congregate living, reduced personal hygiene, and behavioral aberrations such as biting and scratching are thought to enhance disease spread. Among nonretarded, however, the importance of sexual transmission of hepatitis $B$ has been particularly emphasized in male but not female homosexuals. ${ }^{3}$

However, a literature review regarding the potential for this mode of institutional spread yielded conflicting results. One study of a heterogenous group of institutionalized retardates reported a $14.5 \%$ incidence of homosexual behavior. ${ }^{4}$ Another reported such behavior no greater than in the general population, ${ }^{5}$ and yet another stressed its importance but failed to provide quantitative data. ${ }^{6}$ Consequently, a survey of homosexual behavior among a group of ambulatory males aged 19 to 63 , possessing basic self-help skills and averaging a moderate degree of mental retardation in adaptive functioning, was undertaken. The males resided together and constituted a subunit of a residential facility for mentally retarded from which the majority of male community placements had been effected. Data, which were derived from information supplied by staff members in daily 24-hour contact with residents, namely, direct care attendants and nursing personnel, disclosed that 29 of 54 residents $(53 \%)$ engaged in homosexual behavior. The majority $(n=23)$ preferred anal intercourse, whereas substantially fewer $(n=6)$ engaged in oral-genital intercourse. Such activity was typically concentrated during unstructured time, primarily evenings and weekends. Results approximated rates identified in prisons, ${ }^{7}$ but in contrast to the latter setting, group sexual assault was absent and individual assault rare. Review of prevaccination serologic data disclosed that hepatitis B markers were most common $(75 \%)$ in those identified as engaging in receptive anal intercourse, but only slightly lower in both the remaining homosex- ual $(70 \%)$ and nonhomosexual groups $(68 \%)$. No correlation between hepatitis $B$ surface or e antigenemia and sexual orientation or behavior was found, and all homosexually active residents were anti-HTLV-III negative, except one who was positive but Western blot negative.

If these findings are confirmed by a broader data base, it would indicate that a significant portion of ambulatory socially interactive adolescent and adult male retardates returning to the community constitute another small subgroup at increased risk of sexually transmitted disease. In the case of homosexually active hepatitis $\mathrm{B}$ carriers, knowledge of such behavior, confidentially transmitted to local health professionals, could further minimize related spread of that infection in recipient schools and communities. Readmission of homosexually active retardates from communities where HIV infection is likely to be more prevalent should be accompanied by repeat antibody screening because the institutional milieu could favor rapid dissemination of that infection. Whether the sexual behavior of deinstitutionalized retardates will parallel that of former convicts, which reflects a change to heterosexuality for those who had engaged in active (insertor) anal intercourse, and persistence of homosexuality for those involved in receptive anal intercourse, ${ }^{7}$ is unknown and deserves study.

\section{REFERENCES}

1. Bakal C.et al: Mentally retarded hepatitis B surface antigen carriers in NYC: public school classes: A public health dilemma. Am J Public Health 1980; 70:712-716.

2. Chaudhary RK. Perry S, Cleary [E: Prevalence of hepatitis $B$ infection among residents of an institution for the mentally retarded. Am / Epidemiol 1977 ; 105:123-126.

3. Samuness $W$, et al: On the role of sexual behavior in the spread of hepatitis B infection. Ann Intern Med $1975 ; 83: 489-495$.

4. Mitchell L. Doctor R, Butler 1): Attitudes of caretakers toward sexual behavior of mentally retarded persons. Am J Ment Defic 1978; 83:289-296.

5. West R: The sexual behavior of the institutionalized severely retarded. Aust f Ment Retwd 1979; 5:11-13

6. Mulhern I: Survey of reported sexual behavior and policies characterizing residential facilities for retarded citizens. Am J Ment Defic 1975; 79:670-673.

7. Sagarin E: Prison homosexuality and its effect on postprison behavior. Psychiatry 1976; 39:245-257.

George S. Fidone, MD

Medical Director

Texas Department of Mental Health and Mental Retardation Austin, Texas 